NASA / TM-1998-208428

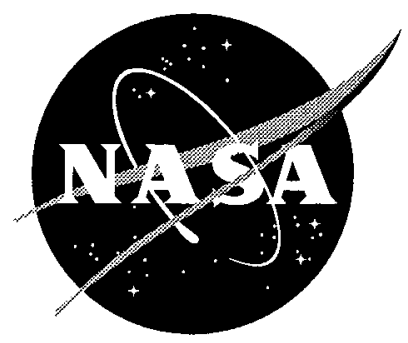

\title{
Analysis of Buckling and Stable Tearing in Thin-Sheet Materials
}

B. R. Seshadri and J. C. Newman, Jr.

Langley Research Center, Hampton, Virginia

National Aeronautics and

Space Administration

Langley Research Center

Hampton, Virginia 23681-2199 



\title{
ANALYSES OF BUCKLING AND STABLE TEARING \\ IN THIN-SHEET MATERIALS
}

\author{
B. R. Seshadri ${ }^{*}$ and J. C. Newman, Jr. \\ NASA Langley Research Center \\ Hampton, Virginia \\ USA
}

\begin{abstract}
This paper was to verify the STAGS (general shell, geometric and material nonlinear) code and the critical crack-tip-opening angle (CTOA) fracture criterion for predicting stable tearing in cracked panels that fail with severe out-of-plane buckling. Materials considered ranged from brittle to ductile behavior. Test data used in this study are reported elsewhere. The STAGS code was used to model stable tearing using a critical CTOA value that was determined from a cracked panel that was "restrained" from buckling. The analysis methodology was then used to predict the influence of buckling on stable tearing and failure loads. Parameters like crack-length to-specimen-width ratio, crack configuration, thickness, and material tensile properties had a significant influence on the buckling behavior of cracked thin-sheet materials. Experimental and predicted results showed a varied buckling response for different crack-length-to-sheet-thickness ratios because different buckling modes were activated. Effects of material tensile properties and fracture toughness on buckling response were presented. The STAGS code and the CTOA fracture criterion were able to predict the influence of buckling on stable tearing behavior and failure loads on a variety of materials and crack configurations.
\end{abstract}

\section{NOMENCLATURE}

B Specimen thickness, $\mathrm{mm}$

$c_{i} \quad$ Initial half-length of crack, mm

d Minimum element size along crack line, $\mathrm{mm}$

E Young's modulus, GPa

* National Research Council Resident Research Associate, NASA Langley Research Center, MS 188E, Hampton, VA 23681 


$\begin{array}{ll}\mathrm{F}_{\mathrm{b}} & \text { Buckling response ratio }\left(\mathrm{P}_{\mathrm{b}} / \mathrm{P}_{\mathrm{nob}}\right) \\ \mathrm{P}_{\mathrm{b}} & \text { Peak load when sheet allowed to buckle, } \mathrm{N} \\ \mathrm{P}_{\mathrm{nob}} & \text { Peak load when sheet restrained from buckling, } \mathrm{N} \\ \mathrm{S} & \text { Applied stress, MPa } \\ \mathrm{S}_{\mathrm{k}} & \text { Peak stress during crack linkup }(\mathrm{k}=1 \text { to } 3), \mathrm{MPa} \\ \mathrm{S}_{\mathrm{f}} & \text { Failure stress, MPa } \\ \mathrm{W} & \text { Out-of-plane displacement in z-direction, mm } \\ \mathrm{w} & \text { Specimen half-width, mm } \\ \mathrm{x}, \mathrm{y}, \mathrm{z} & \text { Cartesian coordinates } \\ \Delta \mathrm{c} & \text { Crack extension, mm } \\ v & \text { Poisson's ratio } \\ \sigma_{\mathrm{xx}} & \text { Normal stress in } \mathrm{x} \text {-direction } \\ \psi_{\mathrm{c}} & \text { Critical crack-tip opening angle, degrees } \\ \psi_{\mathrm{i}} & \quad \text { Critical opening angle for sawcut at crack initiation, degrees }\end{array}$

\section{INTRODUCTION}

Stably tearing cracks in fuselage structures are subjected to complex loading conditions (pressure, biaxial, and shear) and cracks in fuselages are subjected to mixedmode and out-of-plane deformations. In the framework of the NASA Airframe Structural Integrity Program, the FRANC3D/STAGS codes are being developed to predict the behavior of these cracks under complex fuselage loading with the critical crack-tipopening angle (CTOA) fracture criterion [1]. In developing the residual strength methods, the ability of STAGS to predict the influence of bulging or buckling on stable tearing behavior, in the presence of multiple-site and discrete source damage, needed to be verified on laboratory tests and on structural test articles. Development of these residual strength analysis methodologies for complex loading are essential to ensure the continued safe operation of the aging commercial transport fleet and aircraft for the next generation. 
Several fracture criteria have been proposed to predict the residual strength of cracked specimens or structures using the finite-element method. The crack-tip stress or strain, crack-tip-opening angle (CTOA), crack-tip-opening displacement (CTOD), cracktip force, strain-energy-release rate, and the J-integral have been employed to predict the stable crack growth behavior under monotonic loading. Of these, the CTOA or CTOD criterion had been shown to be well suited for modeling the stable crack growth process and instability during fracture [2-4]. Experimental measurements of the critical CTOA during the fracture process for thin-sheet aluminum alloys [5] have shown that CTOA remains nearly constant during stable crack growth after a small amount of crack extension (about one thickness).

Because cracks in fuselage structures are subjected to out-of-plane deformations, the influence of bulging or buckling on stable tearing must be accounted for in the analysis. By addressing a simpler crack problem, such as the fracture behavior of middle-crack tension $\mathrm{M}(\mathrm{T})$ specimens under buckling conditions, an assessment of the capability of the STAGS code and the critical CTOA criterion can be made.

In 1962, Kuhn and Figge [6] developed an expression to determine the buckling response ratio $F_{b}$ (ratio of buckling load to failure load of restrained $M(T)$ specimens with anti-buckling guides) as a function of the initial crack-length-to-thickness $\left(\mathrm{c}_{\mathrm{i}} / \mathrm{B}\right)$ ratio. Later, Forman [7] carried out a series of experiments to determine the effects of buckling and specimen dimensions on residual strength of thin-sheet aluminum alloys and steels. At least two $M(T)$ specimens were tested with guide plates lightly clamped against the panels to prevent buckling and one specimen was tested without guide plates to allow buckling to occur. The test program showed that there was a considerable reduction in residual strength of cracked sheets which were allowed to buckle. From these results the linear relationship given by Kuhn and Figge, to define the buckling response ratio, could not be generalized for most materials. This lack of uniqueness in representing the buckling response ratio with thickness for different materials, and the need to verify the STAGS code and the CTOA fracture criterion, prompted this study. 
The objective of this study was to analyze cracked panels that fail with severe out-ofplane buckling using STAGS (STructural Analysis of General Shells) code [8,9] and the CTOA fracture criterion. Materials with fracture behavior ranging from brittle to ductile were considered. The STAGS code was used to model stable tearing using a critical CTOA value that was determined from a cracked panel that was "restrained" from buckling. The STAGS code and the critical CTOA value were then used to predict the influence of buckling on failure loads. The influence of crack-length-to-specimen-width ratio, thickness, crack configuration and material tensile properties on the buckling behavior on several thin-sheet aluminum alloys and a steel were studied. These materials covered a wide range in fracture toughness behavior and had critical CTOA values ranging from a very low value of 1.9 degrees to a value of 4.6 degrees. Experimental test data used herein are reported elsewhere. A hypothetical material with a 10 degree critical CTOA value was also considered to study the buckling behavior of specimens made of an extremely high toughness material. Comparisons are made between the measured and predicted applied stress against crack extension, in-plane crack-opening displacement (COD) and crack out-of-plane displacement (COPD) for 2024-T3 specimens tested with and without buckling guides. The influence of various buckling modes and the initial crack-length-to-thickness ratio $\left(\mathrm{c}_{\mathrm{i}} / \mathrm{B}\right)$ on failure loads were studied. The effects of material tensile properties and fracture toughness on buckling response are presented and discussed. The influence of multiple-site-damage (MSD) on the buckling response were also studied for some previously conducted tests on 2024-T3 panels. (MSD is the presence of a large number of small fatigue cracks near a large primary lead crack, such as fatigue cracks along a rivet row in a lap-splice joint in a fuselage.) The ability of the STAGS shell code and the CTOA fracture criterion to predict the influence of buckling on stable tearing behavior and residual strength of thin-sheet materials were investigated.

\section{MATERIALS AND SPECIMEN CONFIGURATIONS}

Analyses were conducted on middle-crack tension $\mathrm{M}(\mathrm{T})$ specimens and on multiplesite damage (MSD) specimens subjected to remote tension. The materials studied were 2024-T3, 2219-T87 and 7075-T6 aluminum alloys and an AM355CRT steel. These 
materials cover a wide range in fracture behavior from brittle to ductile. In general, the initial crack-length-to-half-width $\left(c_{i} / w\right)$ ratio of $1 / 3$ was considered but, in addition, the 2219-T87 material was analyzed with $\mathrm{c}_{\mathrm{i}} / \mathrm{w}$ ratios of $0.2,0.4,0.6$ and 0.8 to study the effects of crack length on residual strength. As shown in Table 1, the materials stressstrain behavior were approximated by piece-wise-linear curves.

\section{FINITE ELEMENT ANALYSES}

In the $\mathrm{M}(\mathrm{T})$ specimen, the normal stress, $\sigma_{\mathrm{xx}}$ parallel to the crack surface is compressive, as shown in Figure 1. If the specimen is not restrained, then the crack flanks will deform out-of-plane (buckle) and this behavior will greatly reduce the load carrying capacity. The STAGS code and the CTOA fracture criterion will be used to study stable tearing and buckling interactions in this specimen type.

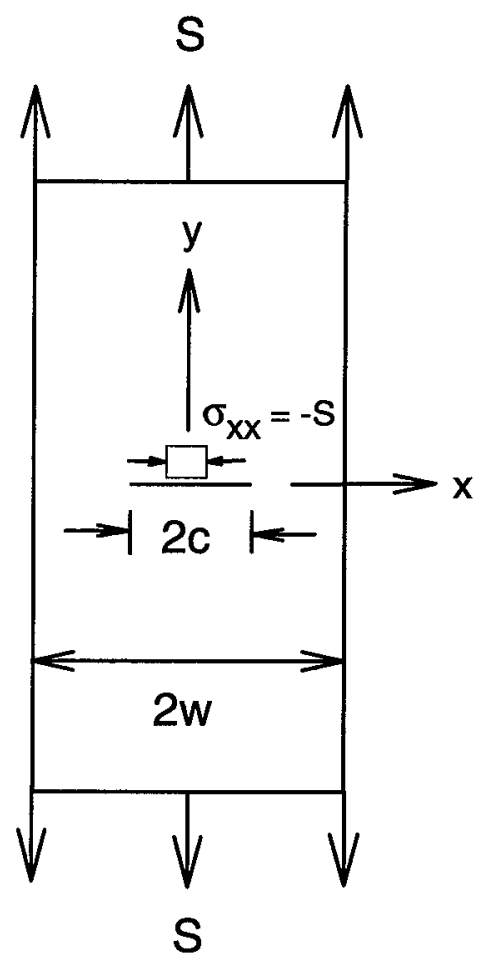

Figure 1. Middle-crack tension, $M(T)$, specimen. 
STAGS is a finite element program for the analysis of general shell-type structures [8, 9]. The program has several types of analysis capabilities (static, dynamic, buckling, crack extension, material nonlinear and geometric nonlinear behavior). STAGS has crack extension capability based on the critical crack-tip-opening angle or displacement (CTOA or CTOD) criterion and the traditional $\mathrm{K}_{\mathrm{R}}$-curve. Its finite element library includes, twonode beam elements, triangular shell, quadrilateral shell and transitional elements to connect triangular and quadrilateral elements (see refs. 8 and 9 for more details). In the current study, quadrilateral shell elements with 6 degrees-of-freedom per node (three displacements and three rotations) were used. The quadrilateral shell element was under "plane-stress" conditions. Elastic-plastic material behavior was approximated by multilinear stress-strain curves (see Table 1). The White-Besseling plasticity theory with a form of kinematic hardening was used to account for yielding and reverse yielding during unloading [9].

The specimen configuration and typical mesh pattern are shown in Figures 1 and 2, respectively. Because the configuration and loading were symmetric, only a quarter of the sheet was modeled, as shown in Figure 2. The minimum crack-tip element size (d) of 1 $\mathrm{mm}$, along the line of crack extension, was chosen to be the same for all meshes generated for different case studies. From previous parametric and convergence studies, it was found that a minimum crack-tip element size of $1 \mathrm{~mm}$ (linear-strain element) was sufficient to model stable tearing under elastic-plastic conditions [10]. Crack growth was governed by monitoring the critical CTOA $\left(\psi_{\mathrm{c}}\right)$ at one element distance $(1 \mathrm{~mm})$ behind the crack tip. In general, the critical value $\left(\psi_{\mathrm{c}}\right)$ was determined by matching the average failure load measured on several tests of $\mathrm{M}(\mathrm{T})$ specimens (restrained from buckling), as will be discussed later.

A critical CTOA $\left(\psi_{\mathrm{c}}\right)$ was used to evaluate the onset of crack growth. This criterion is equivalent to a critical CTOD $\left(\delta_{\mathrm{c}}\right)$ value at a specified distance behind the crack tip. At each load increment, the CTOA was calculated and compared to a critical value $\psi_{\mathrm{c}}$. When the CTOA exceeded the critical value, the crack-tip node was released and the 
crack was advanced to the next node. This process was continued until crack growth became unstable under load control or until the desired crack length had been reached under displacement control.

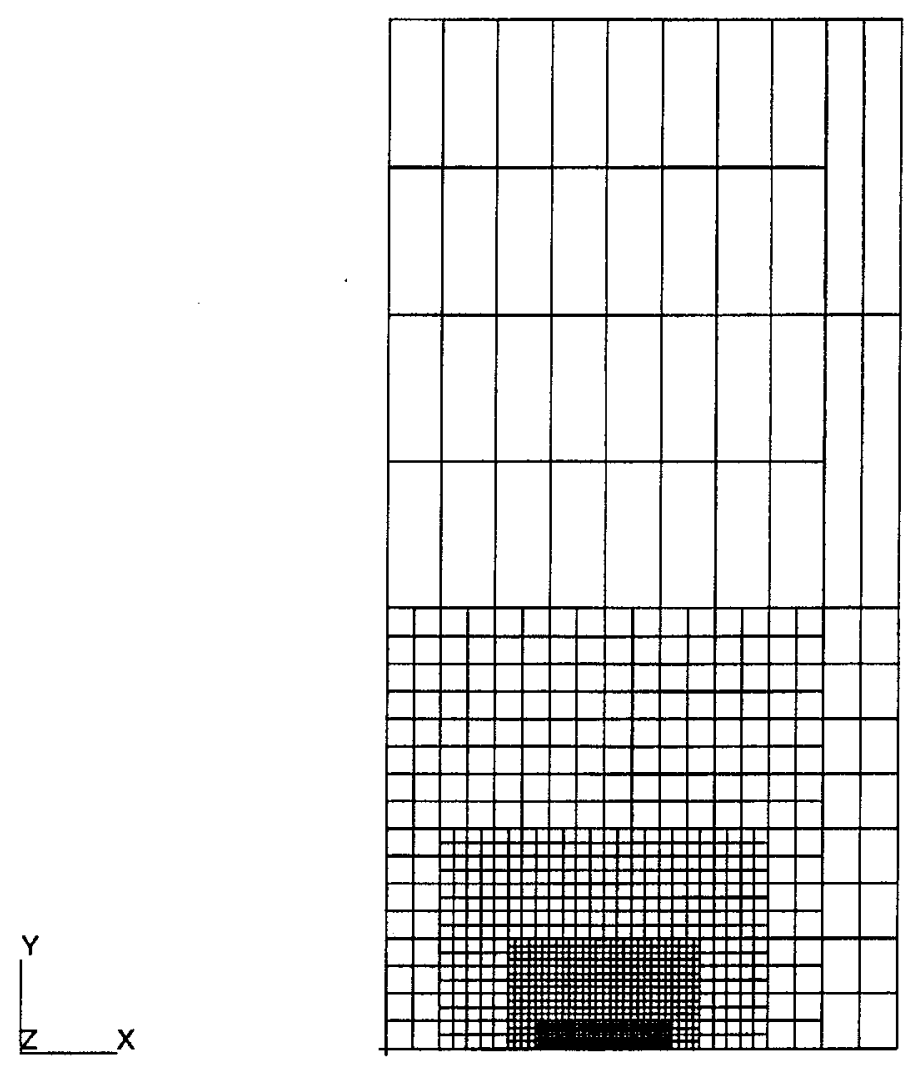

Figure 2. A typical finite-element model of one-quarter of an $M(T)$ specimen.

The aerospace industry frequently uses sawcuts to approximate fatigue cracks because they are less costly to manufacture and they can be placed more accurately in complex structural test articles than an actual fatigue crack. To approximate the use of sawcuts, the sawcut was assumed to undergo a deformation at the sawcut tip before a crack would initiate. In order to simulate the sawcut effects, a critical sawcut angle, $\psi_{i}$, was selected to model the deformations that take place at the sawcut tip before a crack would initiate. Again this value was selected to match the load required to initiate a crack at the sawcut. In the analysis, once the critical sawcut angle was reached, the node at the tip of the sawcut was released and the crack advanced to the adjacent node $(1 \mathrm{~mm}$ 
spacing). Thus, the crack extension at initiation was $1 \mathrm{~mm}$. After a crack had initiated, the critical tearing CTOA, $\psi_{\mathrm{c}}$, was used to grow the crack. The tearing angle, $\psi_{\mathrm{c}}$, and sawcut angle, $\psi_{\mathrm{i}}$, for the different materials considered in the present analyses are listed in Table 2.

In order to simulate buckling in the STAGS numerical analyses, a concentrated load of a very small magnitude was gradually applied in small steps in the transverse or out-ofplane ( $\mathrm{z})$ direction. The concentrated load was applied at the center of the crack $(\mathrm{x}=0)$. A trial-and-error procedure was used to find the small load that was sufficient to induce buckling. The out-of-plane load was gradually reduced as the external loading was applied.

\section{RESULTS AND DISCUSSIONS}

In the following sections, the results of the numerical analyses are compared with the experimental observations and discussed in detail. To begin with, stable crack growth test results, measured crack opening displacements (COD) and measured crack out-of-plane displacements (COPD) are compared with numerical results from fracture simulations. Later, the sawcut simulation capability in STAGS is discussed and analyses are compared with some test results. Finally, the effects of buckling on stable tearing and the influence of multiple-site damage (MSD) cracking on crack growth behavior with buckling are presented.

\section{Fracture Simulations with Fatigue Cracks}

The numerical analyses of $\mathrm{M}(\mathrm{T})$ specimens with and without buckling and the corresponding test data are plotted as applied stress against crack extension in Figure 3.

Square and circular symbols represent the tests conducted with guides to prevent buckling and the triangles show data where guides were not used and the sheet was allowed to buckle [11]. An angle of $\psi_{\mathrm{c}}=4.6$ degrees was used to fit the average of the experimental failure loads corresponding to the specimens with anti-buckling guides (restrained). The dashed curve corresponds to the fracture simulation of the specimens where out-of-plane displacements were restrained. Later, the analysis was repeated with the same angle but buckling was allowed. The solid curve represents the numerical results when out-of-plane 
deformations were permitted (unrestrained). Both the tests and numerical results indicate a significant influence of buckling on stable tearing. The residual strength was drastically reduced when the sheet was allowed to buckle. The experimental and numerical results agreed well near the maximum applied stress but both analyses predicted more crack extension in the early stages of crack growth than in the tests. This discrepancy has been traced to severe crack tunneling [4], since crack extension was measured at the free surface, and to the plane-stress behavior assumed in the analysis [5, 12]. However, these results demonstrate that STAGS and the CTOA criterion can model the influence of buckling on failure loads for cracks in thin-sheet aluminum alloys.

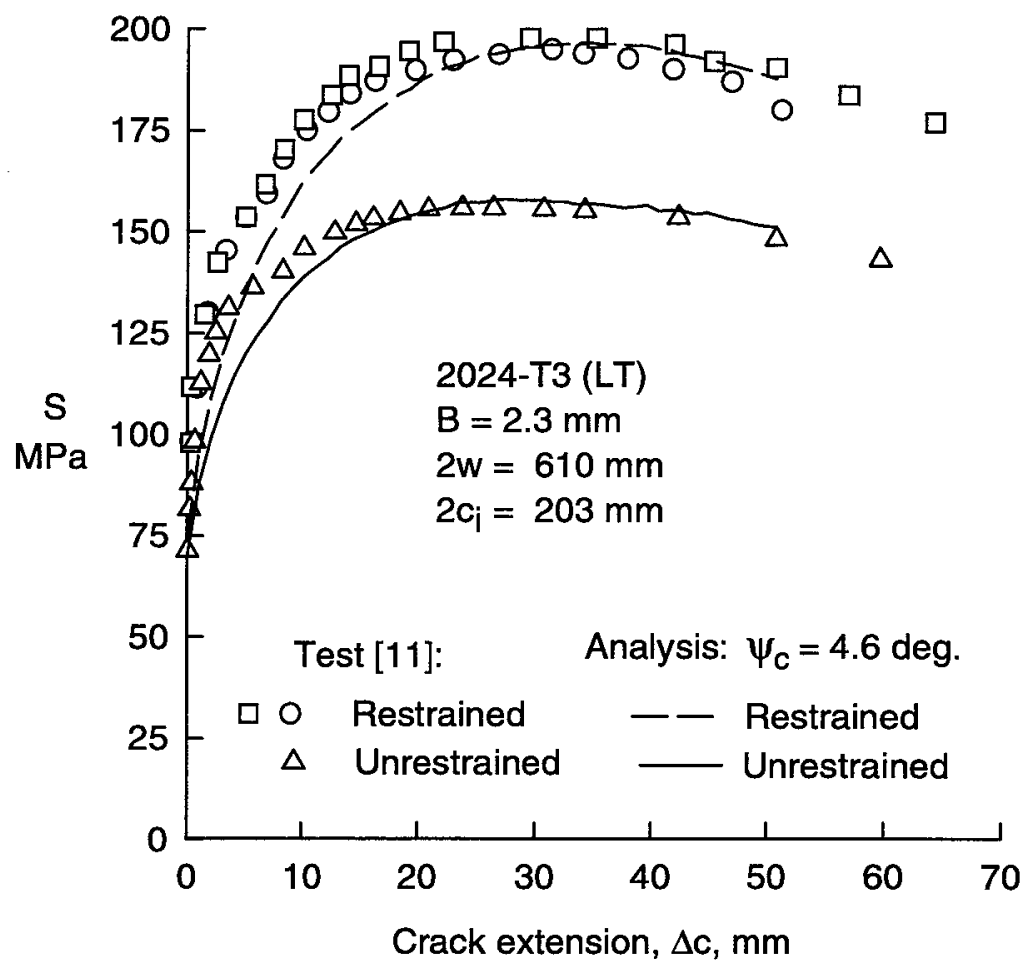

Figure 3. Measured and predicted stable crack growth in $\mathrm{M}(\mathrm{T})$ specimens using CTOA.

Comparison of Measured and Predicted COD--A comparison of applied stress against crack-opening displacement (COD) from the test (symbols) and the STAGS analysis is shown in Figure 4. The crack-opening displacements in the y-direction were measured at the centerline of the crack. Only test results with anti-buckling guides were available for 
comparison [11]. Here, there was good agreement between the tests and numerical results (dashed curve) for the restrained specimens over the complete test range. The solid curve shows the STAGS numerical analyses when out-of-plane displacements were allowed. When out-of-plane deformations were allowed (buckling), the calculated COD values were much larger for a given applied stress than the restrained specimens.

Measured and Predicted Out-of-Plane Displacements--The crack out-of-plane (or transverse) displacements (COPD), measured at the center of the crack $(x=0)$ in the $\mathrm{z}$ direction, are plotted against applied stress in Figure 5. The symbols show the test measurements [11] and the solid curve shows the results from the numerical analysis. After reaching the maximum stress, the numerical results predicted larger COPD values than the test results as the specimen unloaded. This behavior may be attributed to constraint effects because the state-of-stress in the STAGS analysis was plane stress. Higher constraint conditions, such as plane strain, causes a more rapid reduction in the inplane displacements after maximum load [12]. Thus, it was expected that the COPD trends would exhibit a similar behavior after maximum load. Overall the results from the analysis showed good agreement with the test data up to the maximum stress.

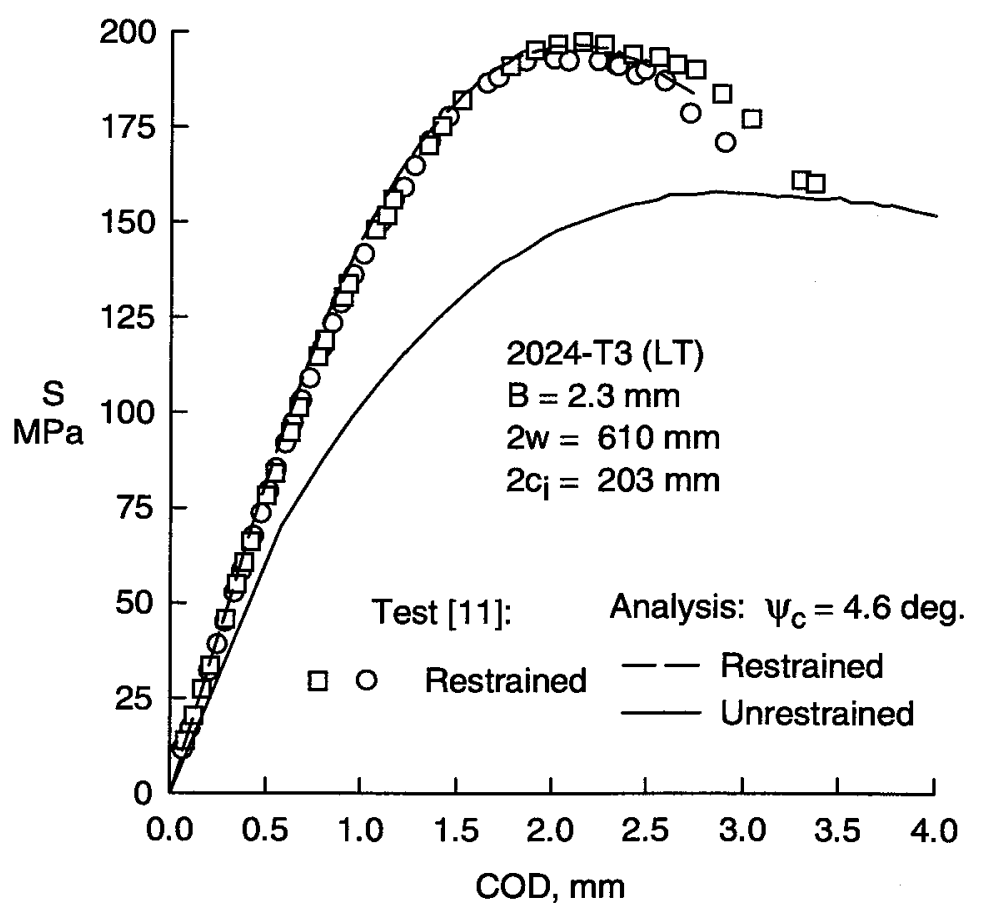

Figure 4. Measured and predicted crack-opening displacement (COD) for $M(T)$ specimen. 


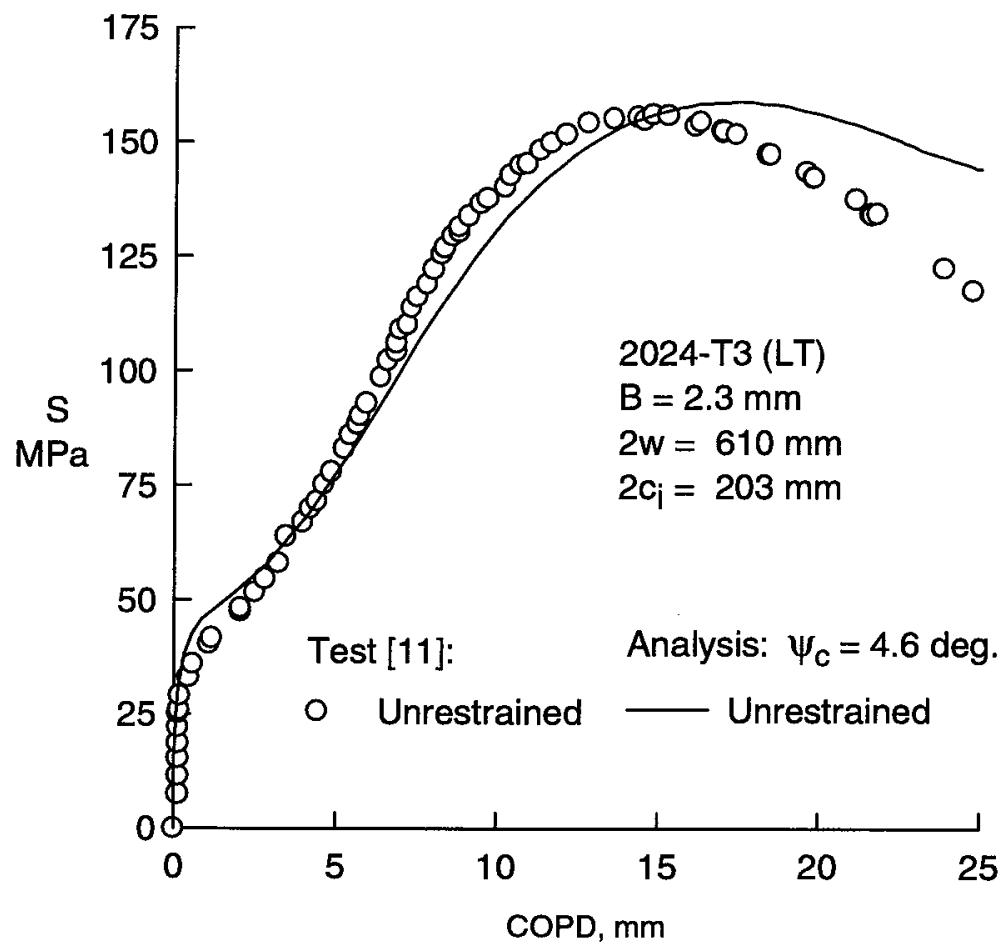

Figure 5. Measured and predicted crack out-of-plane displacement (COPD) for $M(T)$ specimen.

\section{Fracture Simulations with Sawcuts}

Comparison of experimental and numerical applied stress against crack extension for an $\mathrm{M}(\mathrm{T})$ specimen with a sawcut are shown in Figure 6. The test results (symbols) are from a restrained $\mathrm{M}(\mathrm{T})$ specimen with a sawcut (1.8 $\mathrm{mm}$ wide sawcut blade). As previously mentioned, the behavior of sawcuts are quite different from that of a fatigue crack. The sawcut had a blunt tip and required much higher applied stresses to initiate a tearing crack. In order to simulate sawcut effects, a critical sawcut angle, $\psi_{i}$, was selected to match the applied stress required to initiate a crack at the tip of the sawcut, similar to that developed in reference 10 . Once a crack had initiated, the critical tearing angle, $\psi_{\mathrm{c}}$, was used to grow the crack.

Several types of fracture analyses were performed with STAGS. First, a tearing crack was analyzed with a critical angle of 4.6 degrees (dash curve). Then analyses were conducted to find, by trial-and-error, the critical sawcut angle. A sawcut angle of $\psi_{i}=15$ 
degrees was found from these analyses. The solid curve shows the STAGS analysis with the sawcut angle to initiate a crack and a critical angle of $\psi_{\mathrm{c}}=4.6$ degrees to tear the crack. The fit to the experimental results was reasonable. As was evident from Figure 6, the maximum applied stress was not greatly affected by having either a sawcut or crack. But there was a significant difference (about $100 \%$ ) in the initial applied stress required to initiate a crack at the sawcut and the applied stress required to initiate a tearing fatigue crack (see curves at $\Delta c=0$ in the Fig. 6).

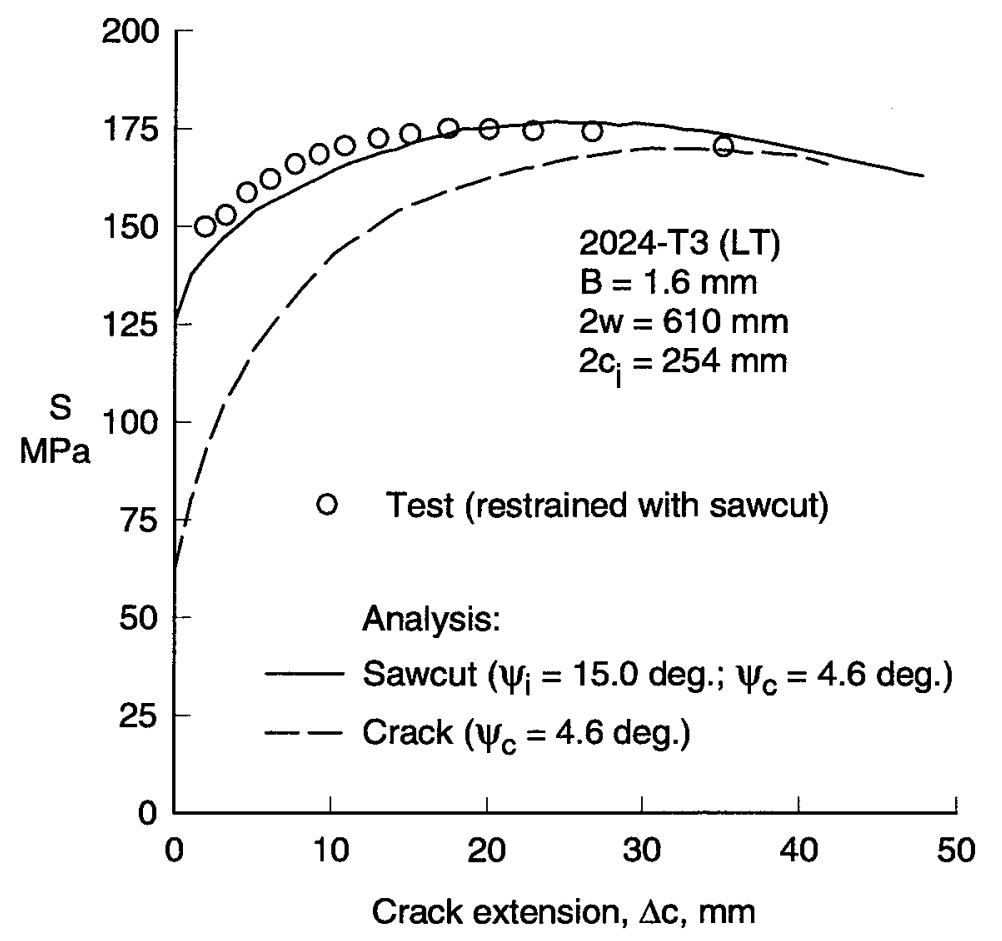

Figure 6. Comparison of measured and calculated stable crack growth in $\mathrm{M}(\mathrm{T})$ specimen with sawcut or crack using CTOA.

\section{Effects of Buckling on Stable Tearing}

Earlier experimental studies $[6,7]$ have shown that parameters like crack-length-towidth ratio $\left(c_{i} / w\right)$, thickness $(B)$, and material tensile properties have a significant influence on the buckling behavior of $\mathrm{M}(\mathrm{T})$ specimens. In order to understand the influence of these parameters, a wide range of materials were considered in the present study (2024-T3, 2219-T87, 7075-T6 aluminum alloys and AM355CRT steel). These 
materials have critical CTOA values from 1.9 to 4.6 degrees. A hypothetical material with a 10 degree critical angle was also considered in the analyses to study the buckling behavior of specimens made of a very ductile material.

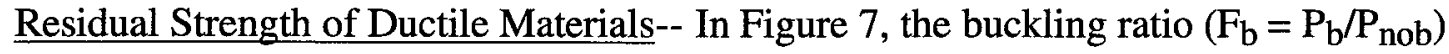
from both experiments and numerical analyses are plotted against the initial crack lengthto-thickness $\left(c_{i} / B\right)$ ratios. $F_{b}$ is the ratio of the peak load $\left(P_{b}\right)$ when the thin sheet was allowed to buckle to the load $\left(\mathrm{P}_{\text {nob }}\right)$ when all out-of-plane displacements are restrained. The results shown in Figure 7 were tested with specimens that had the same crack-lengthto-width ratio, $c_{i} / w=1 / 3$. The specimen widths $(2 \mathrm{w})$ ranged from 75 to $305 \mathrm{~mm}$ for the 1.5-mm thick aluminum alloy and steels [7] and ranged from 75 to $610 \mathrm{~mm}$ for the 2.3$\mathrm{mm}$ thick aluminum alloy [11]. For larger values of the $\mathrm{c}_{\mathrm{i}} / \mathrm{B}$ ratio, the buckling ratio decreased and tended to level off at about 0.7 . Both the aluminum alloys and steels exhibited nearly the same behavior.

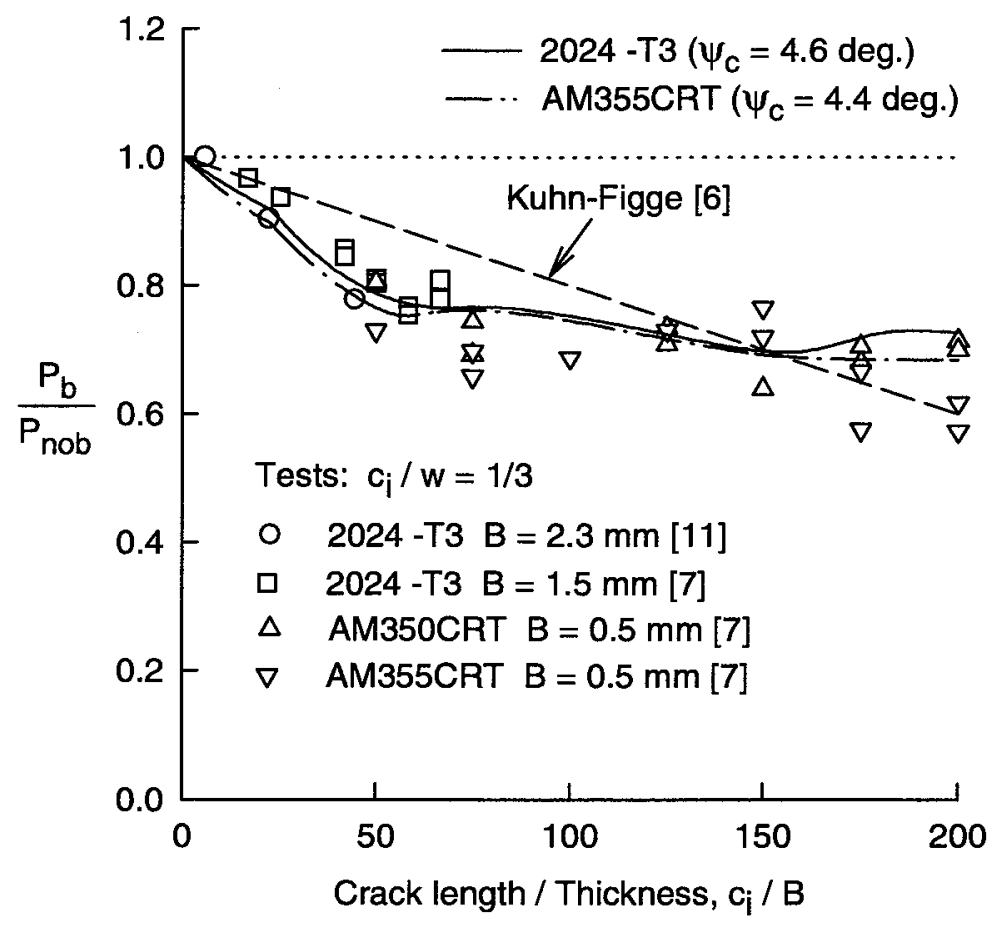

Figure 7. Measured and predicted results for 2024-T3 aluminum alloy and AM355CRT steel. 
For comparison, the linear approximation from Kuhn and Figge [6] was shown as the dashed line. The experimental results from the tests $[7,11]$ for both materials lie on either side of the linear approximation. Thus, the linear relationship can only be considered as a first approximation to the buckling response. Actually, the experimental results show that the behavior was nonlinear.

The STAGS numerical results are shown by solid and dash-dot curves for the aluminum alloy 2024-T3 and AM355CRT steel, respectively. Here the fracture analyses were conducted at various $\mathrm{c}_{\mathrm{i}} / \mathrm{B}$ ratios by varying $\mathrm{B}$ with $\mathrm{c}_{\mathrm{i}} / \mathrm{w}$ as constant $\left(\mathrm{c}_{\mathrm{i}} / \mathrm{w}=1 / 3\right)$. Numerical results compared well with the experimental trends. Both the aluminum alloy and steel predictions show similar buckling response. Their corresponding critical angles $\left(\psi_{\mathrm{c}}\right)$ were 4.6 and 4.4 , respectively. With an increase in the $\mathrm{c}_{\mathrm{i}} / \mathrm{B}$ ratio from 0 to 50 , the buckling ratio dropped linearly from unity to about 0.8 . For $\mathrm{c}_{\mathrm{i}} / \mathrm{B}$ ratios greater than 50 , the buckling ratio decreased slowly and approached a value of about 0.7 , but the buckling ratio oscillated. This nonlinear behavior was suspected to be due to the buckling response shifting from one buckling mode to another. In the initial stage, the buckling response was in the first buckling mode. With an increase in $\mathrm{c}_{\mathrm{i}} / \mathrm{B}$, the sheet reached a critical position and the response shifts into the second buckling mode. This change from the first mode to a higher buckling mode provide an increased resistance to buckling and causes the ratio to decrease at a slower rate. For a $c_{i} / B$ ratio of 200 , the sheet exhibited severe out-of-plane deformations both parallel and perpendicular to the crack surfaces.

In an effort to study the influence of the shift from one buckling mode to another on residual strength, the STAGS/CTOA analysis was conducted on panels with $\mathrm{c}_{\mathrm{i}} / \mathrm{B}$ ratios less than 50, greater than 50 and much larger than 50. The initial crack length was the same for all analyses. The magnitude and direction of the initial out-of-plane load to initiate buckling was the same in all cases. The out-of-plane W-displacement (at the peak stress) is plotted against the $\mathrm{x} / \mathrm{w}$ value in Figure 8 . The results at the smallest $\mathrm{c}_{\mathrm{i}} / \mathrm{B}$ value 
shows the first mode of buckling. For larger $\mathrm{c}_{\mathrm{i}} / \mathrm{B}$ values, the second and third mode of buckling developed.

Residual Strength of Brittle Materials--Forman [7] also conducted fracture tests on various specimens made of 7075-T6 aluminum alloy ( $2 \mathrm{w}$ ranged from 38 to $305 \mathrm{~mm}$ ) with and without buckling guides. The buckling ratio $\left(\mathrm{P}_{\mathrm{b}} / \mathrm{P}_{\text {nob }}\right)$ from these tests are shown as symbols in Figure 9 as function $c_{i} / B$. For the small specimen widths tested, the buckling ratio was, surprisingly, greater than unity on several test series. The reason for this behavior may be specimen scatter because this material is quite brittle in comparison to the 2024-T3 alloy. Again, the dashed line is the simple buckling equation proposed by Kuhn and Figge [6]. Here the Kuhn-Figge expression was in good agreement with the test data.

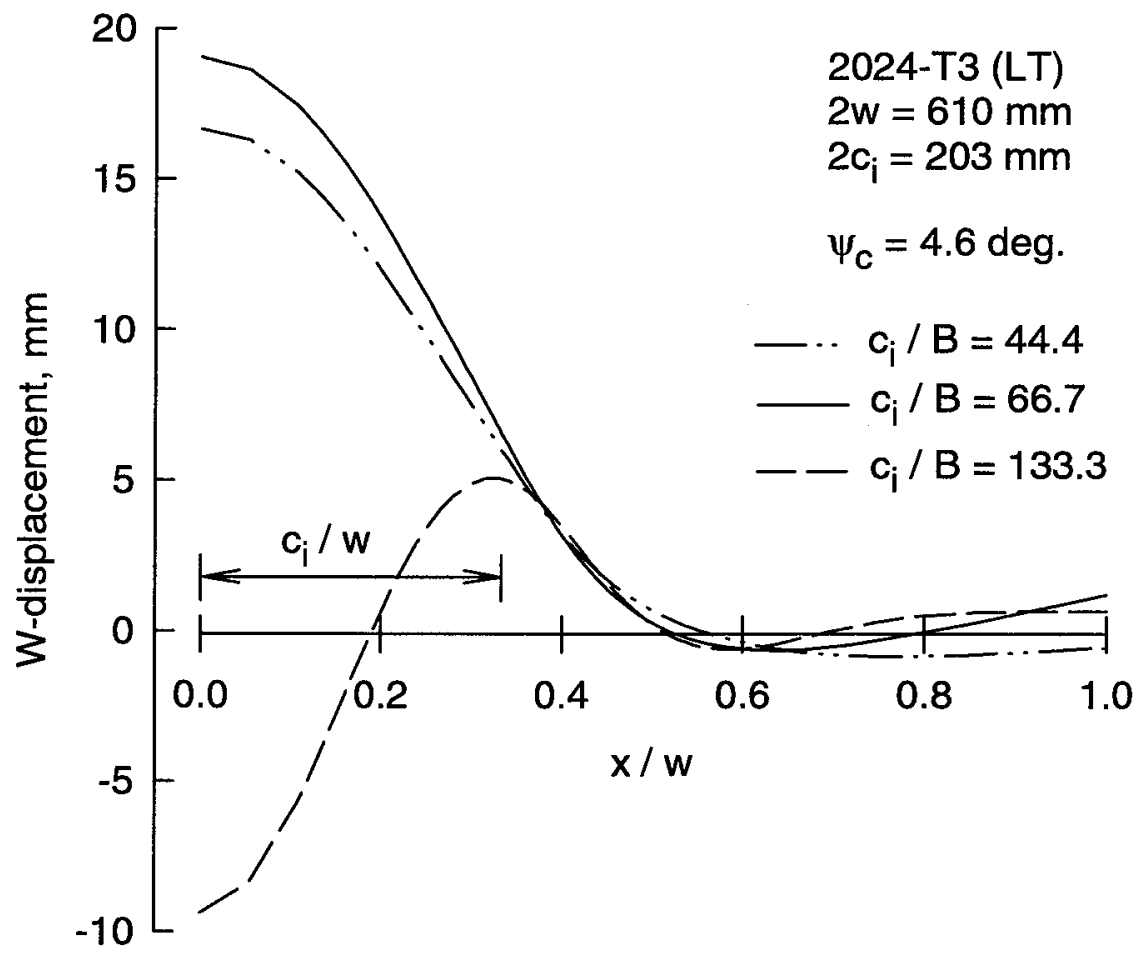

Figure 8. Predicted out-of-plane buckling mode shapes along crack line for 2024-T3 aluminum alloy M(T) specimens.

An analysis with the STAGS code on the restrained 7075-T6 specimens with the largest width produced a critical angle of 1.9 degrees. When the buckling analyses were 
repeated with the 7075-T6 alloy, the buckling response was also linear in the range of $0<$ $\mathrm{c}_{\mathrm{i}} / \mathrm{B}<100$, as shown in Figure 9, but the slope was quite different than that for the 2024T3 alloy and steel, as shown in Figure 7. This material exhibited very small amounts of stable tearing and had very little plastic deformation at the crack tip before fracture. However, there was good correlation between the test results and the numerical analyses with the CTOA concept. These results demonstrate that the buckling response is a strong function of the fracture toughness of the material.

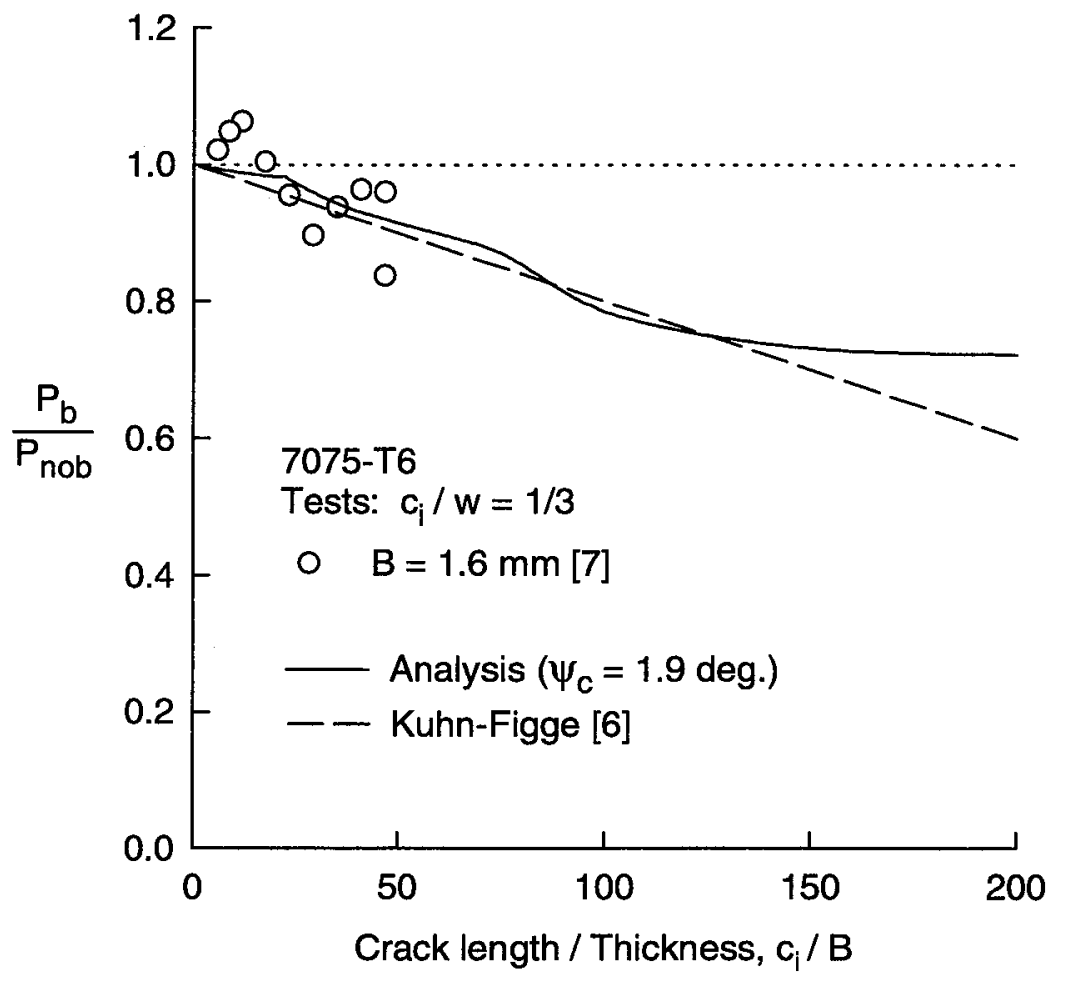

Figure 9. Measured and predicted behavior for 7075-T6 aluminum alloy.

Residual Strength of Hypothetical (Very Ductile) Material--To further study the influence of toughness on the residual strength during buckling, a 2024-T3 aluminum alloy with a hypothetical critical angle, $\psi_{\mathrm{c}}$, of 10 degrees was analyzed. These results are shown in Figure 10. As previously mentioned, this angle was selected to study the effect on buckling when the size of the plastic zone becomes very large compared to the specimen width. For comparison, the residual strength for the same material with a critical 
angle $\left(\psi_{\mathrm{c}}\right)$ of 4.6 degrees is also shown. The analyses showed that buckling had much less influence on the failure loads for the very ductile alloy because the material was failing under net-section yielding conditions. The drop in the buckling ratio over the wide range of $c_{i} / B$ ratios analyzed was only about 10 percent.

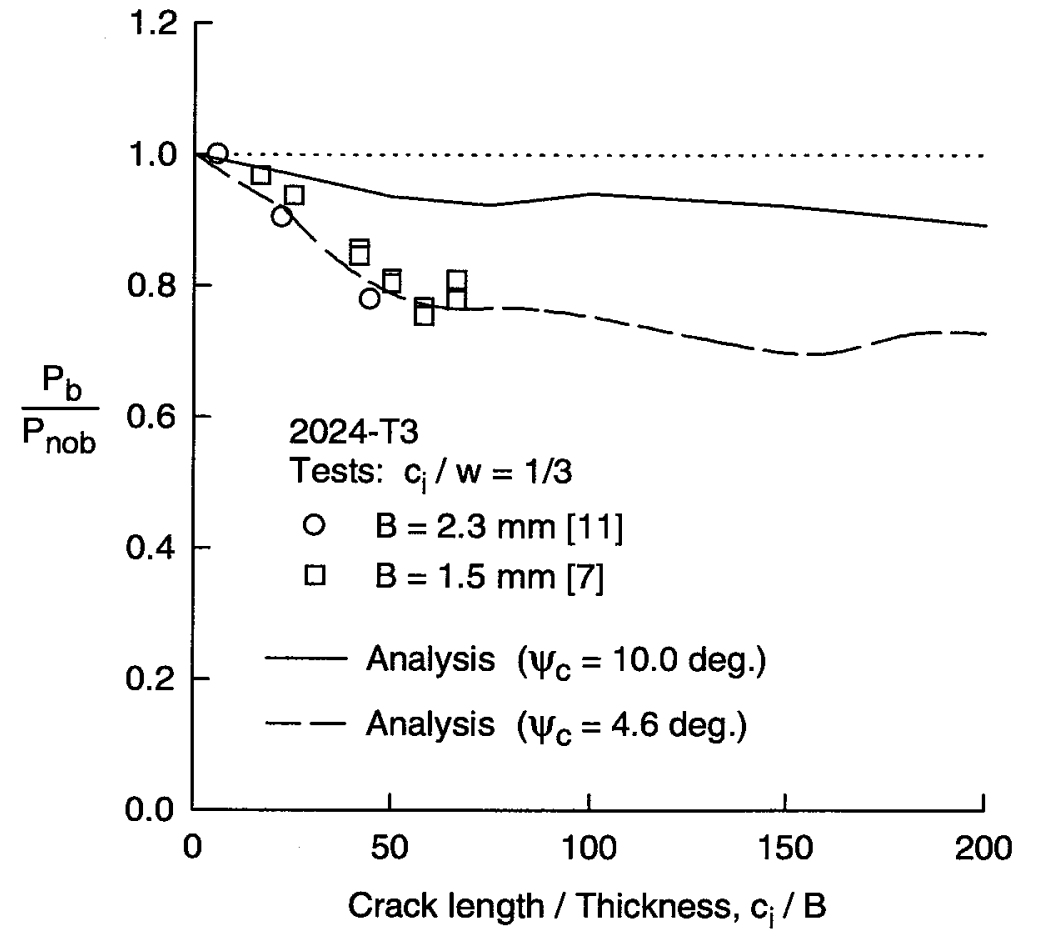

Figure 10. Measured and predicted behavior for two critical CTOA values.

Effect of CTOA on Residual Strength--From Figure 10, it was found that the residual strength of the 2024-T3 aluminum alloy was much less when the critical angle $\psi_{\mathrm{c}}$ was 4.6 degrees instead of 10 degrees. In order to study the tearing-buckling behavior as a function of the critical angle, the buckling response of the 2024-T3 alloy was analyzed with various critical angles from 2 to 10 degrees with a $c_{i} / B$ ratio of 200 . These results are shown in Figure 11. At high angles, the material fails by net-section yielding and buckling had a small influence failure loads (about $10 \%$ ). At the lower angles, the material had low fracture toughness and failure was brittle in nature and, again, buckling had a small influence failure loads. However, for CTOA values between these two 
extreme cases ( 3 to 5 degs.), buckling effects on stable tearing and failure loads were significant. These analyses indicate that buckling response is a strong function of fracture toughness or critical angle.

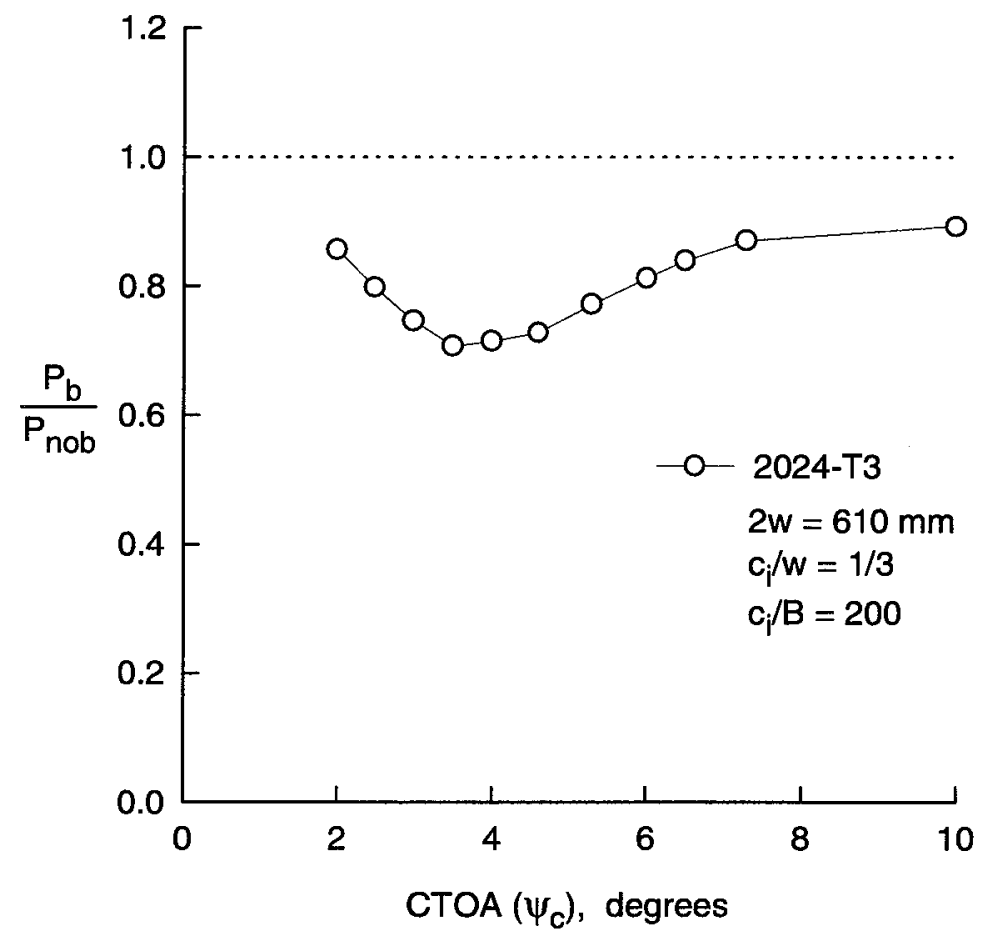

Figure 11. Variation in buckling response ratio with CTOA.

Effect of Crack Length, Width, and Thickness on Residual Strength--In this section, the influence of various crack lengths, widths, and thicknesses on buckling response is presented and discussed. Earlier, the buckling response for 2024-T3 material was obtained at various values of $c_{i} / B$ by varying $B$ and keeping $c_{i} / w$ as constant (Fig. 7). In the present case, the thickness $B$ was held constant $(1.9 \mathrm{~mm})$ and both $c_{i}$ and $w$ were varied while maintaining $c_{i} / w=1 / 3$. The results from these analyses are presented in Figure 12 . For low $\mathrm{c}_{\mathrm{i}} / \mathrm{B}$ ratios, the buckling response was nearly the same by varying either B or w. But the differences in the buckling response are significant in specimens with $\mathrm{c}_{\mathrm{i}} / \mathrm{B}$ ratios greater than 50 . These results suggest that larger panels tend to buckle more and produce lower failure loads than smaller width panels at the same $\mathrm{c}_{\mathrm{i}} / \mathrm{B}$ ratio. 


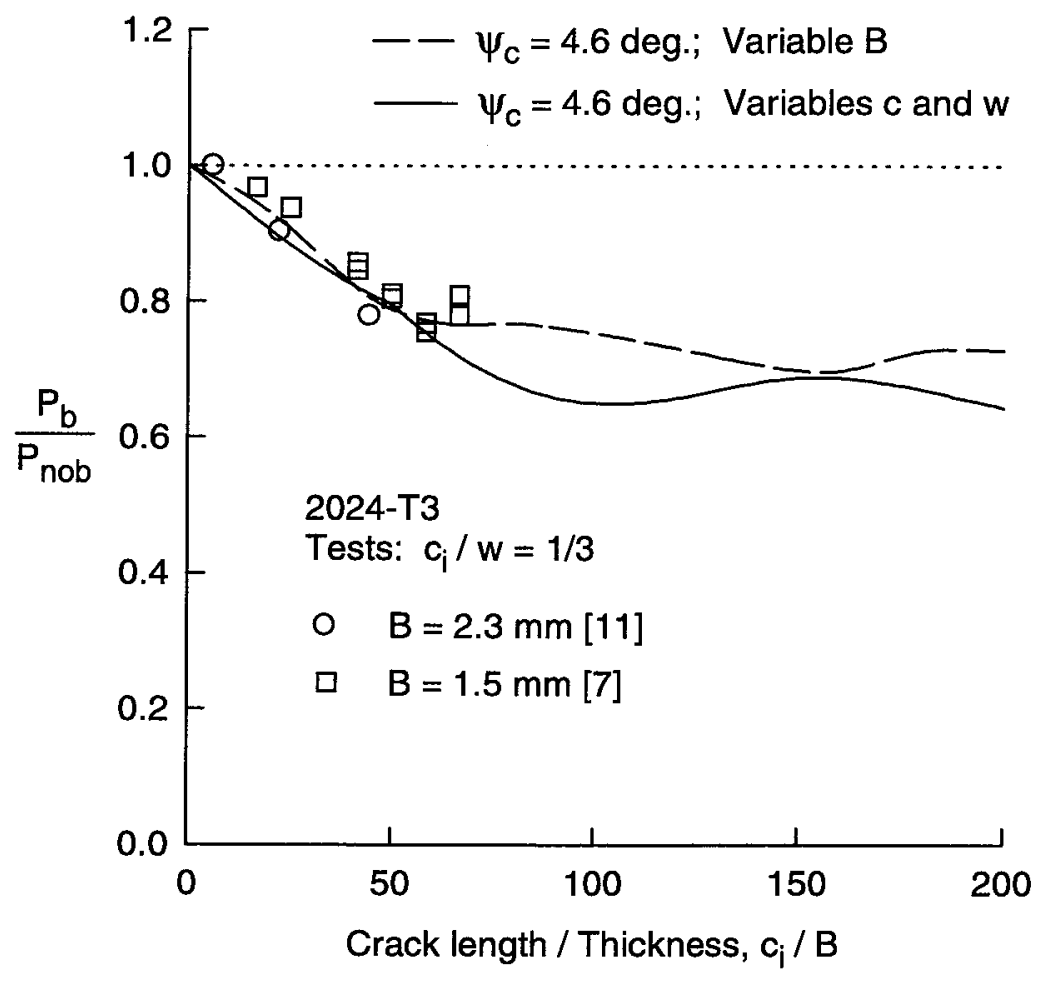

Figure 12. Buckling response ratio in large panels for various thicknesses, crack lengths and widths.

Effect of Crack-Length-to-Width Ratio on Residual Strength--The effects of varying the crack-length-to-width ratio, $c_{i} / w$, on buckling response is shown in Figure 13. Three 510-mm wide ( $2 \mathrm{w})$ panels with various crack lengths were analyzed with buckling to determine the critical angle of 3.6 degrees (unpublished data from Royce Forman, NASA Johnson Space Center). The 2219-T87 aluminum alloy was then analyzed with STAGS using the critical angle of 3.6 degrees for $\mathrm{c}_{\mathrm{i}} / \mathrm{w}$ ratios of $0.2,0.4,0.6$ and 0.8 with $2 \mathrm{w}=$ $510 \mathrm{~mm}$. There were no corresponding test data for the influence of $c_{i} / w$ on buckling response. The numerical results show that the buckling response was a slight function of $c_{i} / w$ with variations of about 10 percent for the various $c_{i} / w$ ratios analyzed. Also, the analyses indicate that the activation of the higher buckling modes, as shown by the oscillatory nature of the buckling response, was weakly dependent upon the $\mathrm{c}_{\mathrm{i}} / \mathrm{w}$ ratios. 


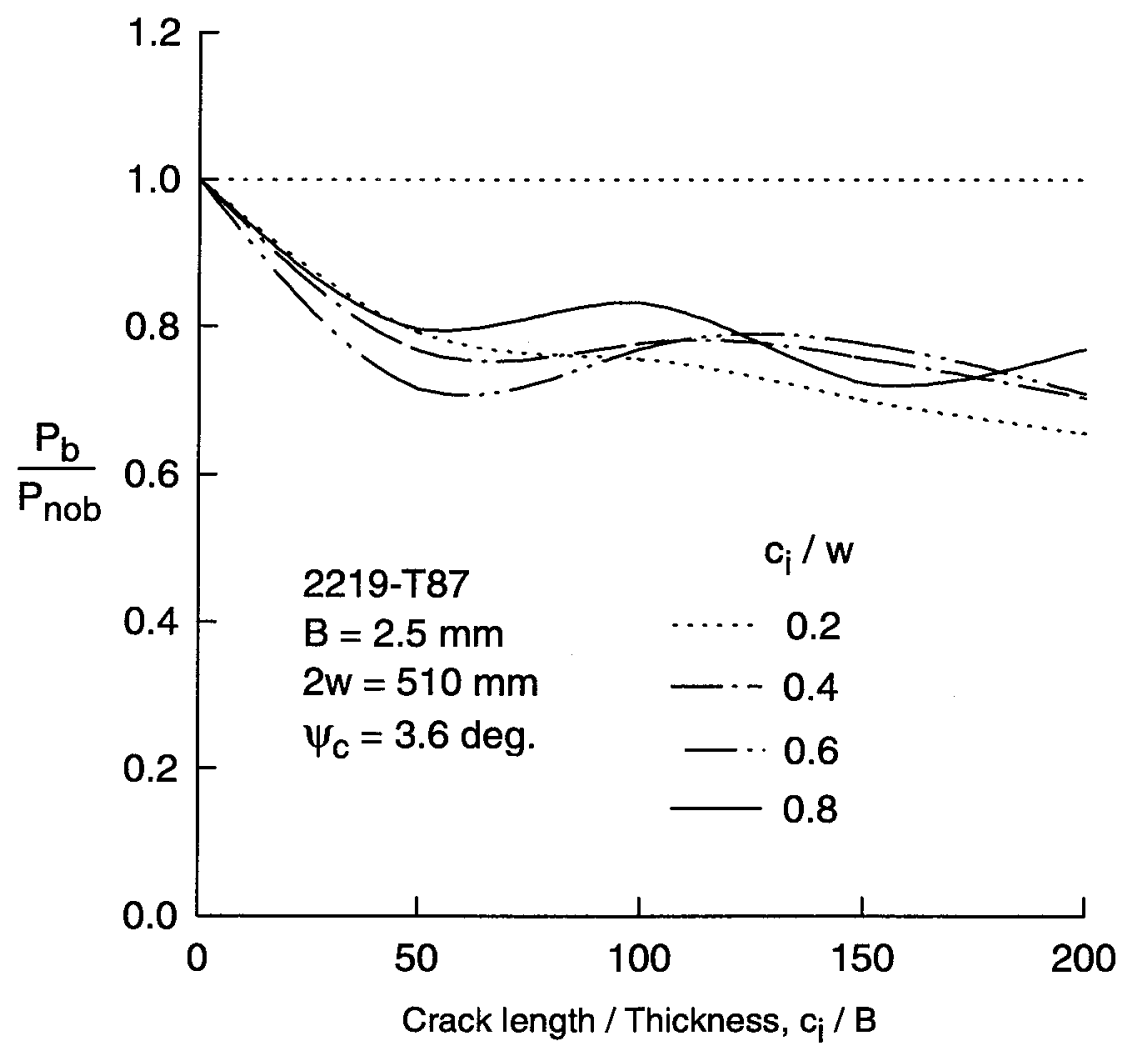

Figure 13. Buckling response ratio as a function of initial crack-length-to-width ratio for 2219-T87 material.

\section{Influence of MSD Cracking on Stable Tearing and Buckling}

Small multiple-site-damage (MSD) cracking at adjacent structural details, such as in a riveted fuselage structure, have a strong influence on residual strength, see Swift [14]. In the previous sections, the effects of buckling on stable tearing in the presence of a single large crack was presented and discussed for various materials. Previously, Newman et al. $[13,15]$ studied the influence of MSD on stable crack growth behavior in 2024-T3 panels. In order to study the influence of buckling on MSD crack behavior, a STAGS analysis was carried out on 2024-T3 MSD panels which had a single large lead crack with two-symmetric MSD cracks on either side of the lead crack (crack number 3), as shown in Figure 14.

Broek et al. [16] conducted fracture tests on 508-mm wide M(T) and MSD specimens made of 2024-T3 Alclad material. Sawcuts were used instead of fatigue cracks. The $\mathrm{M}(\mathrm{T})$ specimens with a single sawcut were tested with initial sawcut lengths 
of 50.8, 88.9 and $140 \mathrm{~mm}$. Experimental data on applied stress, S, against measured crack extension is shown in Figure 15. The critical tearing angle $\psi_{\mathrm{c}}$, and the sawcut angle $\psi_{\mathrm{i}}$, required in the analysis of the MSD panels were determined from an analysis of these specimens and tests on sawcuts reported in reference 10. From the STAGS analyses, a sawcut angle of 8.2 degrees and a critical tearing angle of 4.8 degrees were determined to best fit these data.

From the MSD test [16], the only information reported was the applied stress, S, against crack-opening displacement at the centerline of the lead crack (crack number 3 in Fig. 14). From these results, three peak stresses, $S_{1}, S_{2}$ and $S_{3}$, were identified as the first crack link up, second crack link up and final failure stress, respectively. The maximum stress $S_{\mathrm{f}}$ corresponded to the second peak stress. As these peak stresses could not be related to any particular crack length, they are represented by horizontal lines in the Figure 16. All these test results corresponds to a panel where out-of-plane deformations were prevented with guide plates.

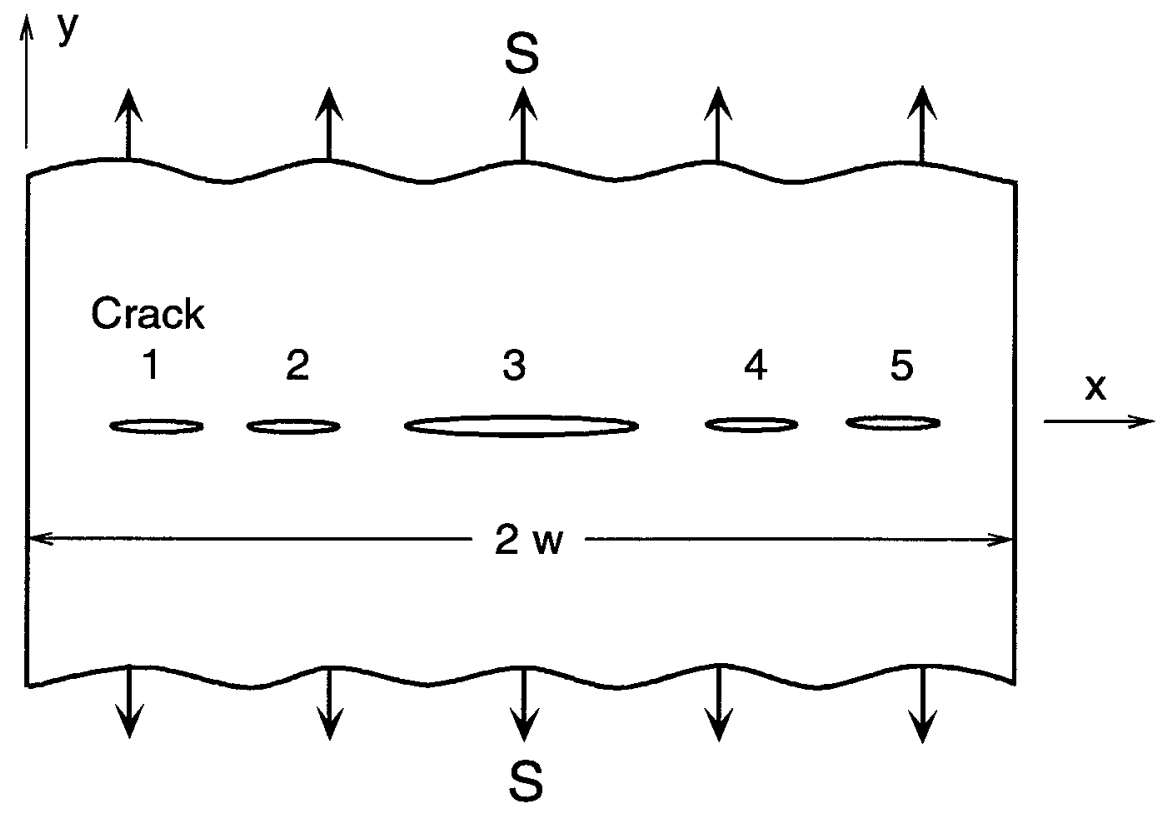

Figure 14. Multiple-site damage (MSD) crack configuration. 


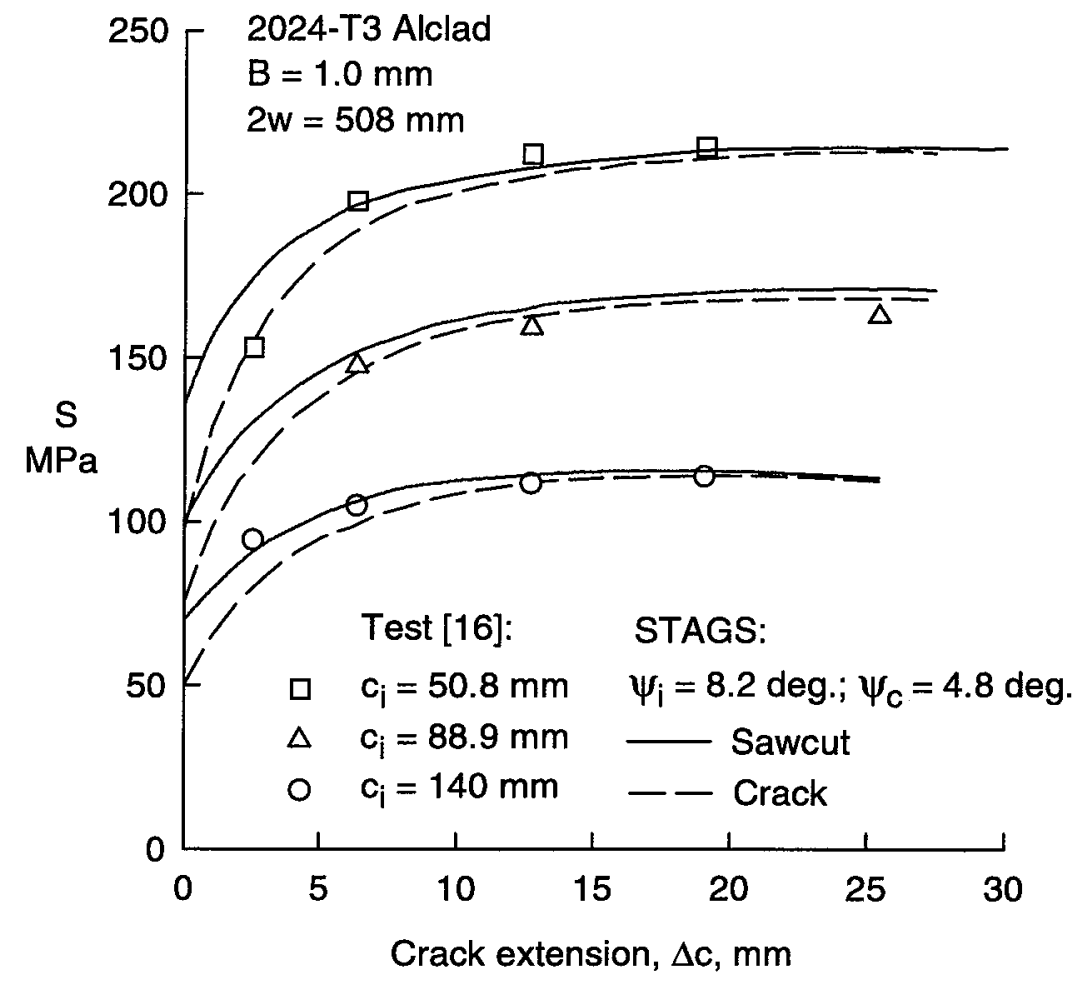

Figure 15. Comparison of measured and calculated stable crack growth in 2024-T3 Alclad aluminum alloy specimens.

In the STAGS analysis of the MSD panel configuration shown in Figure 14, the sawcut and tearing angles determined in the previous section were used. All sawcut tips had the same sawcut and tearing angles. The STAGS analysis was able to predict the three peak stresses quite accurately, as shown in Figure 16.. For comparison, the results from the analysis of a panel with only a lead crack was also shown. The presence of the MSD cracks reduced the residual strength of the panel by 30 percent. When the STAGS analysis was repeated but allowing out-of-plane deformations (buckling), the stress levels at which the cracks link up due to ligament breakage decreased and there was a further reduction (10 percent) in the residual strength of the MSD panel. These analyses indicate that small MSD cracks combined with buckling can significantly reduce the residual strength of MSD panels. 


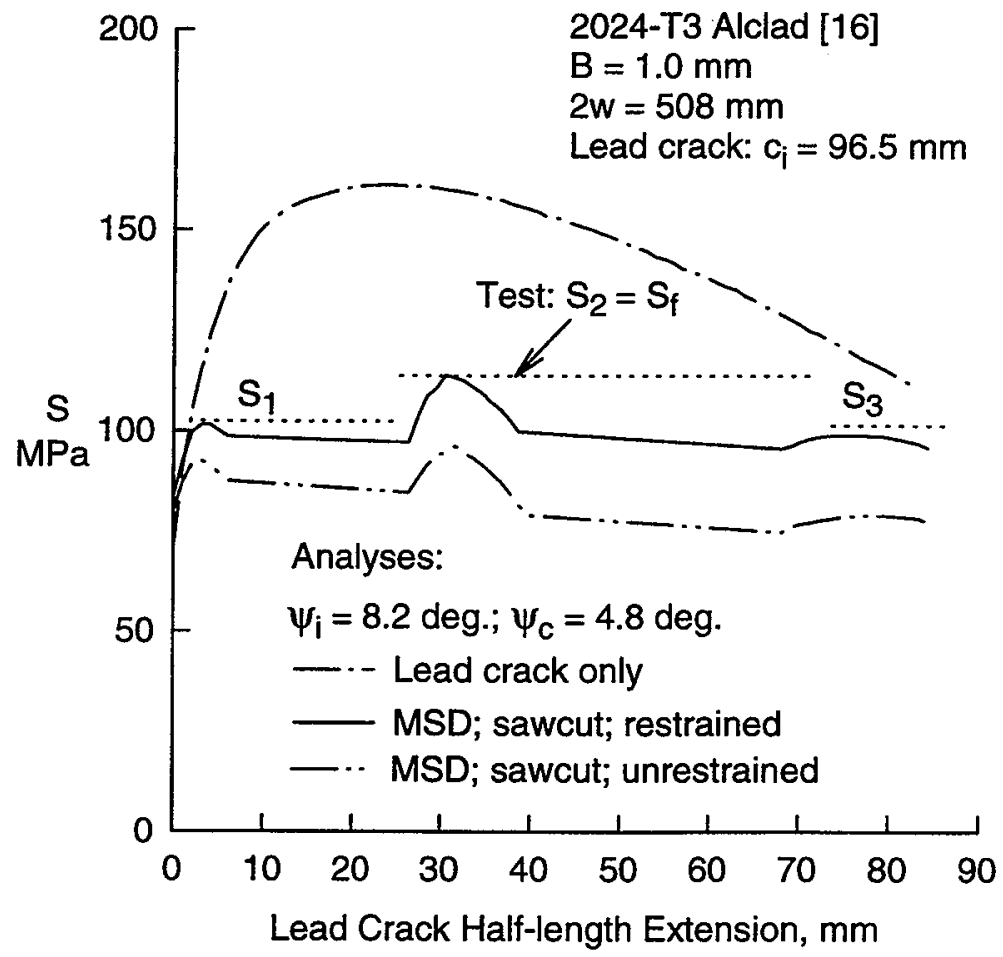

Figure 16. Measured and predicted crack link-up for an MSD panel.

\section{CONCLUDING REMARKS}

Results from the analyses of buckling and stable tearing in thin-sheet materials were presented and discussed. Finite-element fracture simulations using the STAGS shell code with the critical crack-tip-opening angle (CTOA) fracture criterion produced quite accurate results when compared with experimental measurements of crack extension and failure loads. The numerical analyses indicated that sheet thickness (B), crack-length-towidth $\left(c_{i} / w\right)$ ratio, crack configuration, and material fracture toughness had a strong influence on the buckling response. The importance of sawcut simulation in predicting the residual strength of the panels with single sawcuts and multiple-site-damage cracking was highlighted. The STAGS analyses predicted a significant influence of multiple-site damage (MSD) cracking on residual strength. There was a further reduction in residual strength when the MSD panels were allowed to buckle. Finally, the STAGS code and the CTOA fracture criterion may serve as an analysis tool for predicting the residual strength of built-up structures subjected to complex loading conditions. 


\section{ACKNOWLEDGMENT}

This work was performed while the first author was a National Research Council Research Associate at the NASA Langley Research Center.

Table 1. Material stress-strain properties.

\begin{tabular}{|c|c|c|c|c|c|c|c|}
\hline \multicolumn{2}{|c|}{$\begin{array}{l}2024-\mathrm{T} 3(\mathrm{LT}) \\
\mathrm{E}=71.5 \mathrm{GPa} \\
v=0.3\end{array}$} & \multicolumn{2}{|c|}{$\begin{array}{l}7075-\mathrm{T} 6 \\
\mathrm{E}=71.5 \mathrm{GPa} \\
\nu=0.3\end{array}$} & \multicolumn{2}{|c|}{$\begin{array}{l}2219-\mathrm{T} 87 \\
\mathrm{E}=76 \mathrm{GPa} \\
v=0.3\end{array}$} & \multicolumn{2}{|c|}{$\begin{array}{l}\text { AM355CRT } \\
E=207 \mathrm{GPa} \\
v=0.3\end{array}$} \\
\hline$\varepsilon$ & $\sigma, \mathrm{MPa}$ & $\varepsilon$ & $\sigma, \mathrm{MPa}$ & $\varepsilon$ & $\sigma, \mathrm{MPa}$ & $\varepsilon$ & $\sigma, \mathrm{MPa}$ \\
\hline 0.00483 & 345 & 0.00676 & 484 & 0.00455 & 346 & 0.0074 & 1534 \\
\hline 0.015 & 390 & 0.01 & 518 & 0.0074 & 378 & 0.18 & 1666 \\
\hline 0.04 & 432 & 0.02 & 539 & 0.0183 & 411 & 0.25 & 1693 \\
\hline 0.1 & 473 & 0.04 & 560 & 0.0423 & 453 & & \\
\hline 0.16 & 491 & 0.08 & 574 & 0.066 & 464 & & \\
\hline & & 0.14 & 587 & 0.12 & 464 & & \\
\hline & & 0.2 & 588 & & & & \\
\hline
\end{tabular}

Table 2. Critical crack-tip-opening angles for different materials.

\begin{tabular}{lccc}
\hline \multicolumn{1}{c}{ Material } & $\begin{array}{c}\text { Thickness } \\
\text { B, mm }\end{array}$ & $\begin{array}{c}\text { Tearing CTOA, } \psi_{\mathrm{c}} \\
\text { degrees }\end{array}$ & $\begin{array}{c}\text { Sawcut CTOA, } \psi_{\mathrm{i}} \\
\text { degrees }\end{array}$ \\
2024-T3 (LT) & 2.3 & 4.6 & 15.0 \\
2024-T3 Alclad (TL) & 1.0 & 4.8 & 8.2 \\
7075-T6 & 1.6 & 1.9 & \\
2219-T87 & 2.5 & 3.6 & \\
AM355CRT & 0.5 & 4.4 & \\
\hline
\end{tabular}

\section{REFERENCES}

[1] Harris, C. E. and Heyman, J. S., "Overview of NASA Research Related to the Aging Commercial Transport Fleet", Journal of Aircraft, Vol. 30, No. 1, 1993, pp. 64- 68.

[2] Kanninen, M. F., Rybicki, E. F., Stonesifer, R. B., Broek, D., Rosenfield, A. R., Marschall, C. W. and Hahn, G. T., "Elastic-Plastic Fracture Mechanics for TwoDimensional Stable Crack Growth and Instability Problems," Elastic-Plastic Fracture, ASTM STP 668, J. D. Landes, J. A. Begley and G. A. Clarke, Eds., American Society for Testing and Materials, Philadelphia, PA, 1979, pp. 121-150. 
[3] Newman, J. C., Jr., "An Elastic-Plastic Finite-Element Analysis of Crack Initiation, Stable Crack Growth, and Instability," Fracture Mechanics - Fifteenth Symposium, ASTM STP 833, R. J. Sanford, Ed., American Society for Testing and Materials, Philadelphia, PA, 1984, pp. 93-117.

[4] Newman, J. C. Jr., Dawicke, D. S. and Bigelow, C.A., "Finite-Element Analyses and Fracture Simulation in Thin-Sheet Aluminum Alloys", Durability of Metal Aircraft Structures, S. N. Atluri et al., Eds., Atlanta, Georgia, 1992, pp. 167-186.

[5] Dawicke, D. S., Sutton, M. A., Newman, J. C., Jr. and Bigelow, C. A., "Measurement and Analysis of Critical CTOA for an Aluminum Alloy Sheet", Fracture Mechanics: 25th Volume, ASTM STP 1220, F. Erdogan, Ed., American Society for Testing and Materials, Philadelphia, PA, 1995, pp. 358-379.

[6] Kuhn, P and Figge, I.E., "Unified Notch-Strength Analysis for Wrought Aluminum Alloys", NASA TN D-1259, 1962.

[7] Forman, R. G., "Experimental Program to Determine Effect of Crack Buckling and Specimen Dimensions on Fracture Toughness of Thin Materials", Technical Report AFFDL-TR-65-146, January 1966.

[8] Brogan, F. A., Rankin, C. C. and Cabiness, H. D., "STAGS Users Manual", Lockheed Palo Alto Research Laboratory, Report LMSC P032594, 1994.

[9] Almroth, B. O., Brogan, F. A. and Stanley, G. M., "User's Manual for STAGS, Volume I: Theory, NASA CR 165670, March 1978.

[10] Dawicke, D. S. and Newman, J. C., Jr., "Residual Strength Predictions for MultipleSite Damage Cracking using a CTOA Criterion," Fatigue and Fracture Mechanics: 29th Volume, ASTM STP 1332, T. L. Panontin and S. D. Sheppard, Eds., American Society for Testing and Materials, Philadelphia, PA, 1998.

[11] Dawicke, D. S., "Fracture Tests on 0.09 Inch Thick 2024-T3 Aluminum Alloy", NASA TM 112869 , National Aeronautics and Space Administration, 1997.

[12] Newman, J. C., Jr., Booth, B. C. and Shivakumar, K. N., "An Elastic-Plastic FiniteElement Analysis of the J-Resistance Curve using a CTOD Criterion", Fracture Mechanics: Eighteenth Symposium, ASTM STP 945, D. T. Read and R. P. Reed, Eds., American Society for Testing and Materials, Philadelphia, PA, 1988, pp. 665685.

[13] Newman, J. C., Jr.; Dawicke, D. S.; Sutton, M. A. and Bigelow, C. A., "A Fracture Criterion for Widespread Cracking in Thin-Sheet Aluminum Alloys", Durability and Structural Integrity of Airframes, Vol. I, A. F. Blom, Ed., 1993, pp. 443-468. 
[14] Swift, T., "Damage Tolerance in Pressurized Fuselages," New Materials and Fatigue Resistant Aircraft Design, 14th Symposium of the International Committee on Aeronautical Fatigue (ICAF), Ottawa, Canada, June 1987.

[15] Newman, J. C. Jr. and Dawicke, D. S., "Fracture Analysis of Stiffened Panels under Biaxial Loading with Widespread Cracking", Widespread Fatigue Damage in Military Aircraft, AGARD CP-568, 1995, pp. 3.1-3.16.

[16] Broek, D., Thomson, D. and Jeong, D. Y., "Testing and Analysis of Flat and Curved Panels with Multiple Cracks," NASA Conference Publication 3274, Part II, September 1994, pp. 963-984. 

Davis Highway, Suite 1204, Arlington, VA 22202-4302, and to the Office of Management and Budget, Paperwork Reductlon Project (0704-0188), Washington, DC 20503.
1. AGENCY USE ONLY (Leave blank)
2. REPORT DATE
May 1998
TYPE AND DATES COVERED
Technical Memorandum

4. TITLE AND SUBTITIE

Analysis of Buckling and Stable Tearing in Thin-Sheet Materials

5. FUNDING NUMBERS

WU 538-02-10-01

6. AUTHOR(S)

B. R. Seshadri and J. C. Newman, Jr.

7. PERFORMING ORGANIZATION NAME(S) AND ADDRESS(ES)

NASA Langley Research Center

Hampton, VA 23681-2199

L-17747

9. SPONSORING/MONITORING AGENCY NAME(S) AND ADDRESS(ES)

National Aeronautics and Space Administration

Washington, DC 20546-0001

8. PERFORIMING ORGANIZATION REPORT NUMBER

10. SPONSORING/MONITORING AGENCY REPORT NUMBER

NASA/TM-1998-208428

\section{SUPPLEMENTARY NOTES}

Paper published in Fatigue and Fracture Mechanics: 29th Volume, ASTM STP 1332, T. L. Panontin and S. D. Sheppard, Eds., American society for Testing and materials, Philadelphia, PA, 1998.

12a. DISTRIBUTIONAVAILABILITY STATEMENT
Unclassified-Unlimited
$\begin{array}{ll}\text { Subject Category } 39 & \text { Distribution: Standard } \\ \text { Availability: NASA CASI (301) } 621-0390 & \end{array}$

13. ABSTRACT (Maximum 200 words)

This paper was to verify the STAGS (general shell, geometric and material nonlinear) code and the critical cracktip-opening angle (CTOA) fracture criterion for predicting stable tearing in cracked panels that fail with severe out-of-plane buckling. Materials considered ranged from brittle to ductile behavior. Test data used in this study are reported elsewhere. The STAGS code was used to model stable tearing using a critical CTOA value that was determined from a cracked panel that was "restrained" from buckling. The analysis methodology was then used to predict the influence of buckling on stable tearing and failure loads. Parameters like crack-length to-specimenwidth ratio, crack configuration, thickness, and material tensile properties had a significant influence on the buckling behavior of cracked thin-sheet materials. Experimental and predicted results showed a varied buckling response for different crack-length-to-sheet-thickness ratios because different buckling modes were activated. Effects of material tensile properties and fracture toughness on buckling response were presented. The STAGS code and the CTOA fracture criterion were able to predict the influence of buckling on stable tearing behavior and failure loads on a variety of materials and crack configurations.

14. SUBJECT TERMS

Cracks, Crack growth, Crack-tip-opening angle (CTOA), Buckling, Multiple-site damage cracking, STAGS shell code

\begin{tabular}{|c|c|}
\hline 17. SECURITY CLASSIFCATION & $\begin{array}{c}\text { 18. SECURITY CLASSIFICATION } \\
\text { OF REPORT } \\
\text { OfHIS PAGE } \\
\text { Unclassified }\end{array}$ \\
\hline
\end{tabular}

19. SECURITY CLASSIFICATION OF ABSTRACT Unclassified
5. NUMBER OF PAGES 31

16. PRICE CODE $\mathrm{A03}$

20. LIMITATION OF ABSTRACT

Standard Form 298 (Rev. 2-89) Prescribed by ANSI Std. Z-39-18 298-102 